\title{
Post-Embryonic Development of the Antennal Sensilla in Melipona quadrifasciata anthidioides (Hymenoptera: Meliponini)
}

\author{
DIHEGO DE OLIVEIRA AZEVEDO ${ }^{1}$ CIRLEI PEREIRA MATIELLO-GUSS, ${ }^{1}$ MILTON RÖNNAU, ${ }^{2}$ \\ JOSÉ COLA ZANUNCIO, ${ }^{2}$ AND JOSÉ EDUARDO SERRÃO ${ }^{1 *}$ \\ ${ }^{1}$ Departamento de Biologia Geral, Universidade Federal de Viçosa, Av. PH Rolfs, s/n, CEP 36570-000, Viçosa, MG, Brazil \\ ${ }^{2}$ Departamento de Biologia Animal, Universidade Federal de Viçosa, Av. PH Rolfs, s/n, CEP 36570-000, Viçosa, MG, Brazil
}

\begin{abstract}
KEY WORDS Stingless bee; olfactory sensilla; sensillum trichodea; sensillum placodea; SEM
ABSTRACT The sensilla are sensory organs formed by cuticular and cellular structures specialized in reception of chemical and physical stimuli from the environment and transmission to the insect's central nervous system. In function of the great concentration of sensilla, the antennae are the main organs for interaction between bees and with the environment. This work studied the presence of antennal sensilla in the different phases of pupal development of the stingless bee Melipona quadrifasciata anthidioides by means of scanning electron microscopy and light microscopy. The results showed that antennal sensilla begin their development in the transition of the prepupae to the white-eyed pupae and finish it in the pigmented-body pupae phase. The antennal sensilla were exposed to the environment in the black-eyed pupae when the old cuticle is completely digested, suggesting that only in the final pupal phases can these bees perceive the environmental stimuli. Microsc. Res. Tech. 71:196-200, 2008. O 2007 Wiley-Liss, Inc.
\end{abstract}

\section{INTRODUCTION}

Meliponini bees are important plant pollinators in tropical and subtropical regions (Antonini et al., 2006; Heard, 1999) and like other highly eussocial hymenopterans, they present complex behavior which depends upon communication among the nest mates. The antennae are fundamental organs in the interaction between these insects and with the environment, allowing them to locate the colony and food sources, recognize nest mates and facilitating caste management, protection and mating (Downs et al., 2000; Dumpert, 1971; Fresneau, 1979; Free et al., 1992; Lambin et al., 2005; Renthal et al., 2003; Sommeijer and de Bruijn, 1995).

The sensillum is the structural and functional unit of the mechanoreceptors, chemoreceptors, thermo and hygroreceptors, constituted by the association of sensory cuticular structures and sensory cells that are specialized in the reception of chemical and physical stimuli from the environment and transmission to the insect's central nervous system (Chapman, 1998; Keil, 1997; Miller, 1972; Zacharuk and Shields, 1991). The hymenopterans, in general, have six major types of antennal sensilla: basiconica, placodea, coeloconica, trichodea, campaniformia, and ampullacea (Agren and Svensson, 1982; Hashimoto, 1990; Marques-Silva et al., 2006; Olson and Andow, 1993; Renthal et al., 2003; Silva-de-Moraes and Cruz-Landim, 1972; Slifer and Sekhon, 1961).

The sensilla basiconica, placodea, and coeloconica are probably chemoreceptors as they possess uniporous or multiporous cuticular structures. Sensilla trichodea can play the role of chemoreceptors when they present multiporous plate hairs and the role of mechanoreceptors, when the bristles have no pores in the cuticle and are associated with a cuticular basal socket which allows hair movement. Sensilla campaniformia also have no pores in their cuticular structures playing the role of mechanoreceptors. Sensilla ampullacea may be thermo-hygroreceptors and mechanoreceptors (Basibuyuk and Quicke, 1999; Chapman, 1998; Hashimoto, 1990; Kleineidam et al., 2000; Olson and Andow, 1993; Slifer and Sekhon, 1961; Stort and Barelli, 1981; Zacharuck and Shields, 1991).

The cellular components of the sensilla consists of one or more bipolar sensorial neurons surrounded by three accessory cells, also named sheath cells, that sheath in the neurons and their appendages: the inner thecogen cell, the trichogen cell, and the outer tormogen cell which makes contact with the undifferentiated epidermal cells (Chapman, 1998; Keil, 1997; Zacharuck and Shields, 1991). The sensilla can present more than three sheath cells, when some of the three cellular types appear duplicated (Kuhbandner, 1984; Martini 1986a,b; Martini and Schmidt, 1984; Schmidt and Kuhbandner, 1983). The axons from different sensory neurons joining at the antennal lumen form the antennal nerve that links the antennal lobe of the insect brain (Brockmann and Brückner, 1995; Couto et al., 2005; Kelber et al., 2006; Steiner and Keil, 1995).

In general, the antennal sensilla develops in the pupal stage of holometabolous insects (Eichmuller and Schafer, 1995; Schmidt and Kuhbandner, 1983;

\footnotetext{
*Correspondence to: José Eduardo Serrão, Departamento de Biologia Geral, Universidade Federal de Viçosa, Av. PH Rolfs, s/n, CEP 36570-000, Viçosa, MG, Brazil. E-mail: jeserrao@ufv.br

Received 11 May 2007; accepted in revised form 18 September 2007

Contract grant sponsors: CAPES, CNPq, FAPEMIG (Brazilian Research Agencies).

DOI 10.1002/jemt.20539

Published online 8 November 2007 in Wiley InterScience (www.interscience. wiley.com).
} 
Snodgrass, 1956; Steiner and Keil, 1995; Zimmermann, 1991), when a single precursor cell arises in the epidermal surface and differentiates into neurons and sheath cells, followed by the formation of the sensory cuticle structures (Keil, 1997; Ray and Rodrigues, 1995). Apart from the importance of these organs in bee behavior, there are few data on antennal sensilla postembryonic development. The purpose of this work was to verify the presence of antennal sensilla in the different phases of pupal development of Melipona quadrifasciata anthidioides (Lepeletier, 1836).

\section{MATERIALS AND METHODS}

Melipona quadrifasciata anthidioides workers in prepupae (pharate pupae), pupae and adult phases were obtained from colonies in Viçosa, state of Minas Gerais, Brazil maintained in the Apiary of the Federal University of Viçosa.

\section{Scanning Electron Microscopy}

The scanning electron microscopy (SEM) analyses were conducted using antennae obtained from prepupae, white-eyed pupae, pink-eyed pupae, brown-eyed pupae, black-eyed pupae, pigmented-body pupae, and newly-emerged adult workers. The antennae were dissected in insect saline solution, fixed in Zamboni's solution (Stefanini et al., 1967), dehydrated in graded ethanol series, transferred to hexamethyldisilazane (HMDS) for $10 \mathrm{~min}$, and air dried. These antennae were then coated with a 20 -nm thick gold layer and analyzed with a LEO VP1430 SEM.

\section{Light Microscopy}

The histological analyses were conducted with antennae obtained from white-eyed pupae, pink-eyed pupae, brown-eyed pupae, black-eyed pupae, pigmented-body pupae, and newly-emerged adult workers. The antenna were dissected in insect saline solution, fixed in Zamboni's solution (Stefanini et al., 1967), dehydrated in graded ethanol series and embedded in JB4 historesin. The 5 - $\mu \mathrm{m}$ thick sections were stained with hematoxylin and eosin.

\section{RESULTS}

The prepupal antenna presented the scape, pedicel, and the flagellum already determined (Figs. 1 and 2). The prepupae, white-eyed pupae, pink-eyed pupae, and brown-eyed pupae did not present external sensilla structures in the cuticle that covers the antenna (Figs. 1-5). In the black-eyed pupae, this cuticle covering the developing antenna was completely digested and the sensilla placodea, trichodea, and basiconica could be observed in the antenna surface (Fig. 6). In the pigmented-body pupae and newly-emerged adult worker antenna, the sensilla maintained the morphology exhibited in the black-eyed pupae although they covered more surface area (Fig. 7).

The white-eyed pupae showed cuticle in apolysis without sensilla structures. The old cuticle separated from the epidermis formed the exuvial space filled with molting fluid which will bath some developing sensilla structures. At first, the epidermal cells showed some degree of differentiation characterized by groups of acidophilic cells with rounded nuclei, descondensed chromatin and evident nucleolus. Some cells presented extensions directed to the antennal lumen (Fig. 8). Later, in the older white-eyed pupae, these cells display more advanced differentiated aspects allowing the identification of neurons and sheath cells (Fig. 9). The neurons were groups of basophilic cells with rounded nuclei and evident nucleolus displaced at the base of the epidermis, which emitted projections to the cuticle and to the antennal lumen. The sheath cells are represented by cells with light cytoplasm and large nuclei presenting descondensed chromatin and evident nucleolus displaced beneath the antennal surface (Fig. 9). Axons from different groups of neurons join and form a thin antennal nerve displaced near the trachea (Figs. 9 and 10).

The old cuticle without sensilla remains around the pink-eyed pupae antenna. The antennomers which will form the adult antennal flagellum were defined. The trichogen cell apical process could be observed forming pegs and acidophilic spaces around the antennal surface (Fig. 10). These shaped spaces correspond to developing sensilla placodea. The pegs were linked to the neuron projections directed to the antenna surface which were evolved by the sheath cells. The sheath cells' nuclei increased in size. The antennal nerve could be observed at the antennal lumen (Fig. 10). The histological analyses also showed that the sensillogenic regions were not present all over the antenna, being limited to their dorsal surface.

In the light-brown-eyed pupal antenna, the histological analyses showed sensilla hairs already defined despite the thin and flexible cuticle. The developing sensilla placodea could be seen between the hairs. The developing sensilla trichodea did not present a defined articulation region, and the cuticle was not yet a basal socket (Fig. 11). The dark-brown-eyed pupa showed sensilla structures and antennae with a thicker and slightly sclerotized cuticle. The hairs were more upstanding while the sensilla placodea could be clearly observed with the cuticle articulation region already defined and associated dendrites (Fig. 12). In these phases, the sheath cells display nuclei varying from fusiform and rounded forms. The nucleolus remains evident (Figs. 11 and 12).

In the black-eyed pupae, the cuticle remains thin and slightly sclerotized. The cuticle articulation regions of the sensilla placodea and trichodea could be seen at the antennal surface, together with the associated dendrites. The sheath cells maintain their nuclei shape with descondensed chromatin and evident nucleolus (Fig. 13).

The pigmented-body pupae presented completely developed antennal sensilla. The cuticle was thicker and sclerotized, allowing the receptor lymph cavity, the sheath cells that wrap it and associated dendrites to be viewed (Fig. 14). The ventral region without sensilla showed the thickest cuticle (Fig. 15). The newlyemerged adult worker antenna presented the same morphological pattern displayed by the pigmentedbody pupae antenna (Fig. 16).

\section{DISCUSSION}

In holometabolous insects, antennal sensilla development occurs in the pupal phase (Eichmuller and Schafer, 1995; Hansen and Hansen-Delskamp, 1983; Keil and Steiner, 1990; Kuhbandner, 1984; Schmidt and Kuhbandner, 1983; Snodgrass, 1956; Steiner and Keil, 1995; Zacharuck and Shields, 1991). According to Keil 

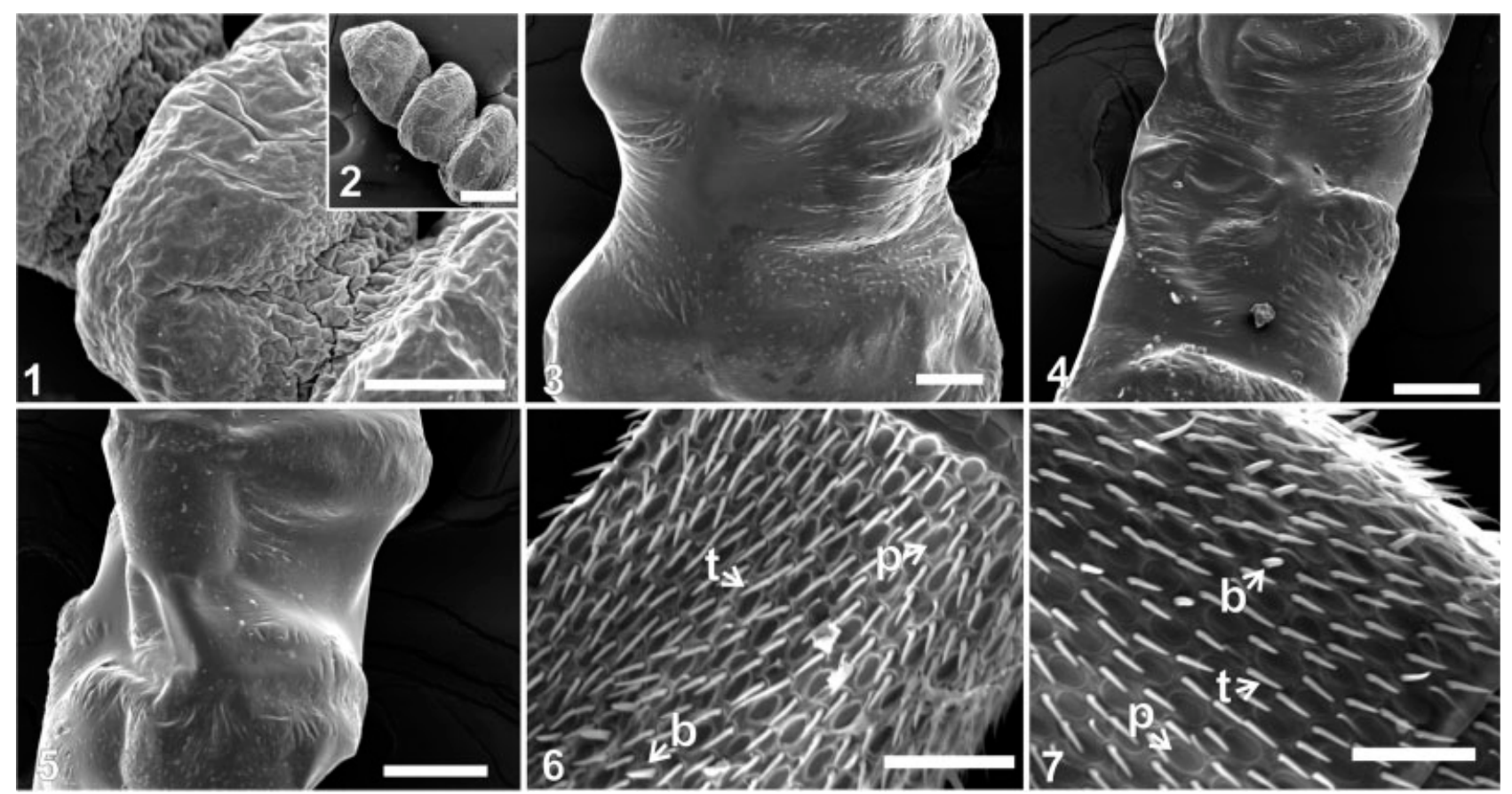

Figs. 1-7. Scanning electron micrograph of the antennae of Melipona quadrifasciata anthidioides worker at different developmental pupal phases. Fig. 1: Larval cuticle without sensilla in the prepupae antennae. Bar $=75 \mu \mathrm{m}$. Fig. 2: Prepupae antennae showing the antennomers of the flagellum. Bar $=150 \mu \mathrm{m}$. Fig. 3: White-eyed pupae antennae showing the cuticle without sensilla. Bar $=60 \mu \mathrm{m}$. Fig. 4: Pink-eyed pupae antennae recovered by the old cuticle without sensilla. Bar $=100 \mu \mathrm{m}$. Fig. 5: The old cuticle in the brown-eyed pupae antennae. Bar $=100 \mu \mathrm{m}$. Fig. 6: Black-eyed pupae antennae. Bar $=40 \mu \mathrm{m}$. Fig. 7: Newly-emerged worker antennae displaying sensilla more spaced among itself than in the black-eyed pupae phase. Bar $=40 \mu \mathrm{m}$. (b) sensillum basiconica; ( $)$, sensillum placodea; $(\mathrm{t})$, sensillum trichodea.

(1997), antennal sensilla morphogenesis begins with the differentiation of the epidermal cells in sensory neurons and the sheath cells. The neurons emit dendrites to the antennal surface which are wrapped in a thin electron-dense sheath created by the thecogen cell that wraps around the neurons. The results presented here suggest that the antennal sensilla development in M. quadrifasciata begins at the transition of the prepupae to the white-eyed pupae phase because in this last phase the cuticle is in apolysis and the epidermal cells are already differentiated in sheath cells and neurons with axons and primary dendrites. According to Eichmuller and Schafer (1995), sensory neuron development in Apis mellifera antenna begins with the onset of the pupal phase. In bees, the prepupa is not a separate phase of the postembryonic development, but it is a pupa covered by the previous apolysized larval cuticle (Snodgrass, 1956), so our results are in agreement with Eichmuller and Schafer (1995). In Antheraea polyphemus (Lepidoptera: Saturniidae) pupae, the antennal epidermis differentiates into sensillogenic and nonsensillogenic regions at the first day after cuticle apolysis (Keil, 1992; Keil and Steiner, 1990, 1991).

According to Hansen and Hansen-Delkeskamp (1983), the trichogen apical process arises after the primary dendrite development in the sensory hairs unfolding in Protophormia terraenovae (Diptera: Calliphoridae). Ameismeier (1985) related that the sensory neuron projections to the cuticle emerge before the trichogen apical process which will form the olfactory sensilla cuticular hairs. In A. polyphemus pupae, the primary dendrites and axons develop on the second day after the cuticle apolysis while the trichogen cells give rise to the apical process after the third day (Keil and Steiner, 1991). Our results showed similar observations in $M$. quadrifasciata where the neuron projections were already present in the white-eyed pupae before the trichogen apical process growth in the pinkeyed pupae phase.

In M. quadrifasciata, the cuticular structures of the antennal sensilla begin to develop in the pink-eyed pupae phase when the trichogen apical process can be observed as small pegs and plates in the antennal surface. Kuhbandner (1984) describes the sensilla basiconica in Calliphora erytrocephala (Diptera) beginning with the growth of the hair forming cell to the exuvial space. In $A$. polyphemus, the apical process which forms the cuticular hairs emerges from the trichogen cell at the third day of the pupal stage, reaching their final length over the 9th day and followed by cuticle secretion. The cuticular structures of the sensilla basiconica had their development completed around the 12 th day, while the sensilla trichodea were completed at day 14 (Keil and Steiner, 1991).

The antennal sensilla of $M$. quadrifasciata reach their final length at the end of the brown-eyed pupae phase when the cuticle deposition in the sensilla anlagen begins. The cuticle that covers and forms the sensory hairs begins to be deposited by the trichogen cells when the apical process reaches the hair's final length (Keil, 1997; Keil and Steiner, 1991; Kuhbandner, 1984; Martini and Schmidt, 1984). In the black-eyed pupae 

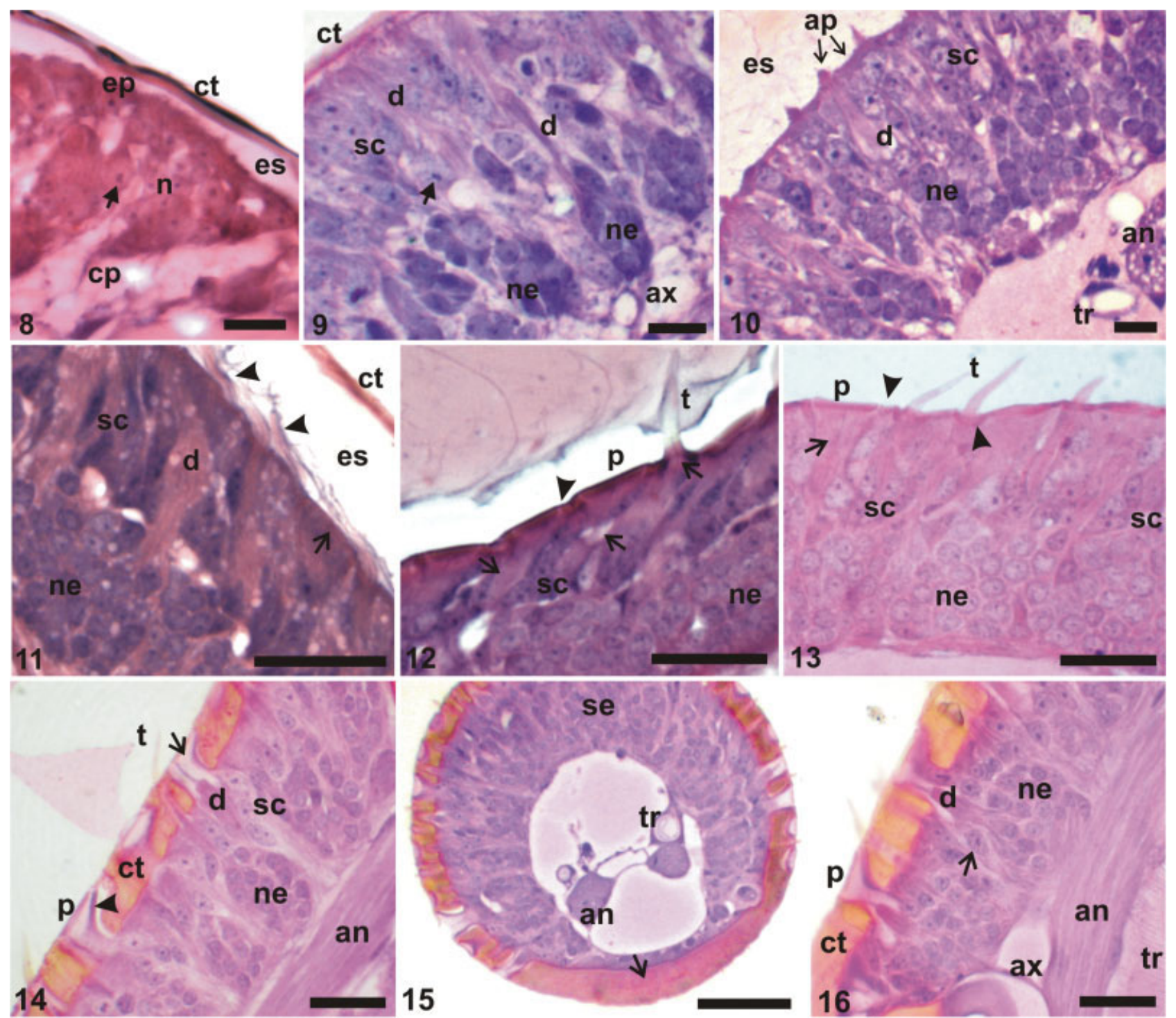

Figs. 8-16. Antennae of Melipona quadrifasciata anthidioides. Fig. 8: White-eyed pupae showing cuticle in apolysis and the differentiating epidermal cells. (cp) cellular prolongations; (arrow) nucleolus; (ep) epidermal surface; Bar $=15 \mu \mathrm{m}$. Fig. 9: Older-white-eyed pupae showing sheath cell nucleus and groups of neurons with dendrites and axons. Bar $=10 \mu \mathrm{m}$. Fig. 10: Pink-eyed pupae showing the trichogen cell apical process (ap) making sensory hairs and plates. Notice the dendrites linked to the developing hairs. Bar $=10 \mu \mathrm{m}$. Fig. 11: Brown-eyed pupae showing the sensory hairs (arrowhead) and the sensilla placodea areas (arrow) with associated dendrites coming from groups of neurons. Bar $=$ $15 \mu \mathrm{m}$. Fig. 12: Dark-brown-eyed pupae showing the sensilla trichodea and placodea with cuticle articulation regions (arrowhead) and associated dendrites (arrow). Notice the thin and few sclerotized cuticle. Bar $=15 \mu \mathrm{m}$. Fig. 13: Black-eyed pupae showing sensilla trichodea and placodea. Note the dendrites displaced in the sensilla basal region (arrow). Sensilla socket (arrowhead). Bar $=20 \mu \mathrm{m}$. Fig. 14: Pigmented-body pupae showing completely developed sensilla with a thick and sclerotized cuticle. The receptor lymph cavity (arrow) can be observed together with the thin cytoplasm of the sheath cell that covers it (arrowhead) and the associated dendrites. Bar $=20 \mu$ m. Fig. 15: Pigmented-body pupae showing the ventral region of antennae with a thick cuticle without sensilla (arrow). Sensory epidermis (se); Bar $=100 \mu \mathrm{m}$. Fig. 16: Newlyemerged worker showing the same morphological pattern of the last pupal phase antenna. (arrow) sheath cells; (ax) bundle of axons. Bar = $20 \mu \mathrm{m}$. (an) antennal nerve; (ax) axons; (ct) cuticle; (d) dendrites; (es) exuvial space; (n) nucleus; (ne) neurons; (p) sensillum placodea; (sc) sheath cells; (t) sensillum trichodea; (tr) trachea.

phase of $M$. quadrifasciata, the sensilla show their characteristic cuticular structures, despite the cuticular components are not yet completely formed and the receptor lymph cavity was not present. According to Keil (1997) the cuticle precursor material packed in electron-dense vesicles is transported on microtubules to the apical process surface where it is released by exocytosis. When cuticle deposition is finished, the trichogen apical process retracts by means of retrograde transport of endocytic vesicles. The trichogen and tormogen cells retract their cytoplasm and form the subcuticle receptor lymph cavity (Hansen and Hansen-Delkeskamp, 1983; Keil, 1997; Keil and Steiner, 1991; Kuhbandner, 1984; Zimmermann, 1991).

According to Cruz-Landim and Höfling (1972), the antennal lobe of $M$. quadrifasciata begins to develop 
from the tritocerebrum in the white-eyed pupae phase while the brain take its final adult form in the browneyed pupae phase. These data associated with our observations suggest that antennal lobe development is related to the onset of sensilla and antennal nerve formation. However, a thicker and sclerotized cuticle, the presence of the receptor lymph cavity and the maintenance of the antennal morphology in the adult phase suggests that antennal sensilla development in $M$. quadrifasciata ends at the body pigmented pupae phase, indicating that the sensilla only complete their formation after brain and antennal lobe development. In this fashion, the morphological aspects of the antennal sensilla development in $M$. quadrifasciata suggest that only in older pupae can these bees perceive environmental stimuli.

\section{ACKNOWLEDGMENTS}

The authors thank the Microscopy and Microanalysis Research Center of the Universidade Federal de Viçosa and to Dr. Simon Luke Elliot for English revision and critical reading of the manuscript.

\section{REFERENCES}

Agren L, Svensson BG. 1982. Flagellar sensilla of Sphecodes bees (Hymenoptera: Halictidae). Zool Scripta 11:45-54.

Ameismeier F. 1985. Embryonic development and molting of the antennal coeloconic no pore- and double-walled pore sensilla in Locusta miqratoria (Insecta. Orthopteroidea). Zoomorphology 105:356-366.

Antonini Y, Costa RG, Martins RP. 2006. Floral preferences of a neotropical stingless bee. Melipona quadrifasciata Lepeletier (Apidae: Meliponina) in an urban forest fragment. Braz J Biol 66:463-471.

Basibuyuk HH, Quicke DLJ. 1999. Gross morphology of multiporous plate sensilla in the Hymenoptera (Insecta). Zool Scripta 28:51-67.

Brockmann A, Brückner D. 1995. Projection pattern of poreplate sensory neurones in honey bee worker. Apis mellifera L. (Hymenoptera: Apidae). Int J Insect Morphol Embryol 24:405-411.

Chapman RF. 1998. The insects: Structure and function, 4th ed. Cambridge: Cambridge University Press. 770 p.

Couto A, Alenius M, Dickson BJ. 2005. Molecular, anatomical and functional organization of the Drosophila olfactory system. Curr Biol 15:1535-1547.

Cruz-Landim C, Höfling JF. 1972. The post-embryonic changes in Melipona quadrifasciata anthidioides Lep. (Hym. Apoidea) V. Development of the nervous system. Pap Avulsos Zool 26:137-147.

Downs SG, Ratnieks FLW, Jefferies SL, Rigby HE. 2000. The role of floral oils in the nestmate recognition system of honey bees (Apis mellifera L.). Apidologie 31:357-365.

Dumpert K. 1971. Alarmstoffrezeptoren auf der antenne von Lasius fuliginosus (Latr.) (Hymenoptera. Formicidae). J Comp Physiol 76:403-425.

Eichmuller S, Schafer S. 1995. Sensory neuron development revealed by taurine immunocytochemistry in the honeybee. J Comp Neurol 352:297-307.

Free JB, Ferguson AW, Simpkins JR. 1992. The behavior of queen honeybees and their attendants. Physiol Entomol 17:43-55.

Fresneau D. 1979. Etude du role sensoriel de l'antenne dans l'ethogenese des soins aux cocons chez Formica polyctena Forst. (Hymenoptera: Formicidae). Insect Soc 26:170-195.

Hansen K, Hansen-Delskamp E. 1983. The development of taste and tactile hairs in the pharate fly Protophormia terraenovae (Diptera. Calliphoridae) and in the embryonal cricket Acheta domestica (Orthopteroidea, Ensifera). Zoomorphol 102:241-259.

Hashimoto Y. 1990. Unique features of sensilla on the antennae of Formicidae (Hymenoptera). J Appl Entomol Zool 25:491-501.

Heard TA. 1999. The role of stingless bees in crop pollination. Ann Rev Entomol 44:183-206.
Keil TA. 1992. Fine structure of a developing insect olfactory organ: Morphogenesis of the silkmoth antenna. Microsc Res Tech 22:351-371.

Keil TA. 1997. Comparative morphogenesis of sensilla: A review. Int J Insect Morphol Embryol 26:151-160.

Keil TA, Steiner C. 1990. Morphogenesis of the antenna of the male silkmoth, Antheraea polyphemus. I. The leaf-shaped antenna of the pupa from diapause to apolysis. Tissue Cell 22:319-336.

Keil TA, Steiner C. 1991. Morphogenesis of the antenna of the male silkmoth, Antheraea polyphemus. III. Development of olfactory sensilla and the properties of hair-forming cells. Tissue Cell 23:821851.

Kelber C, Rössler W, Kleineidam CJ. 2006. Multiple olfactory receptor neurons and their axonal projections in the antennal lobe of the honeybee Apis mellifera. J Comp Neurol 496:395-405.

Kleineidam C, Romani R, Tautz J, Izidoro N. 2000. Ultrastructure and physiology of the $\mathrm{CO}_{2}$ sensitive sensillum ampullaceum in the leaf-cutting ant Atta sexdens. Arthrop Struct Dev 29:43-55.

Kuhbandner B. 1984. Ultrastructure and ontogeny of the hair sensilla on the funicle of Calliphora erythrocephala (Insecta: Diptera). Zoomorphology 104:373-385.

Lambin M, Déglise P, Gauthier M. 2005. Antennal movements as indicators of odor detection by worker honeybees. Apidologie 36:119-126.

Marques-Silva S, Matiello-Guss CP, Delabie JHC, Mariano ASF, Zanuncio JC, Serrão JE. 2006. Sensilla and secretory glands in the antennae of a primitive ant: Dinoponera lucida (Formicidae: Ponerinae). Microsc Res Tech 69:885-890.

Martini R. 1986a. Fine structure and development of the large sensilla basiconica on the antennae of sphecid wasps. Tissue Cell 18:143-155.

Martini R. 1986b. Ultrastructure and development of single-walled sensilla placodea and basiconica on the antennae of the Sphecoidea $(\mathrm{Hy}-$ menoptera: Aculeata). Int J Insect Morphol Embryol 15:183-200.

Martini R, Schmidt K. 1984. Ultrastructure and early development of the pore plate sensilla of Gymnomerus laevipes (Shuckard) (Vespoidea, Eumenidae). Protoplasma 119:159-231.

Miller MC. 1972. Scanning electron microscopy studies of the flagellar sense receptors of Peridesmia discus and Nasonia vitripennis (Hymenoptera: Pteromalidae). Ann Entomol Soc Am 65:1119-1124.

Olson DM, Andow DA. 1993. Antennal sensilla of female Trichogramma nubilale (Ertle and Davis) (Hymenoptera: Trichogrammatidae) and comparisons with other parasitic Hymenoptera. Int $\mathrm{J}$ Insect Morphol Embryol 22:507-520.

Ray K, Rodrigues V. 1995. Cellular events during development of the olfactory sense organs in Drosophila melanogaster. Dev Biol 167: 426-438.

Renthal R, Velásquez D, Olmos D, Hampton J, Wergin WP. 2003. Structure and distribution of antennal sensilla of the red imported fire ant. Micron 34:405-413.

Schmidt K, Kuhbandner B. 1983. Ontogeny of the sensilla placodea on the antennae of Aulacus striatus Jurine (Hymenoptera: Aulacidae). Int J Insect Morphol Embryol 12:43-57.

Silva-de-Moraes RLM, Cruz-Landim C. 1972. Estudo comparativo de órgãos sensoriais em abelhas com diferentes tipos de comunicação. Rev Bras Biol 32:185-196.

Slifer EH, Sekhon SS. 1961. Fine structure of the sense organs on the antennal flagellum of the honey bee, Apis mellifera. Linnaeus. J Morphol 109:351-381.

Snodgrass RE. 1956. Anatomy of the honey bee, 1st ed. New York: Comstock Publishing Associate. $334 \mathrm{p}$.

Sommeijer MJ, de Bruijn LLM. 1995. Drone congregations apart from the nest in Melipona favosa. Insect Soc 42:123-124.

Stefanini M, Demartino C, Zamboni L. 1967. Fixation of ejaculated spermatozoa for electron microscopy. Nature 216:173-174.

Steiner C, Keil TA. 1995. Morphogenesis of the antenna of the male silkmoth. Antheraea polyphemus. V. Development of the peripheral nervous system. Tissue Cell 27:275-288.

Stort CA, Barelli N. 1981. Genetic study of olfactory structures in the anatennae of two Apis mellifera subspecies. J Kansas Entomol Soc $54: 352$.

Zacharuck RY, Shields VD. 1991. Sensilla of immature insects. Ann Rev Entomol 36:331-354.

Zimmermann B. 1991. Differentiation of the thermo-hygrosensitive (no-pore) sensilla on the antenna of Antheraea pernyi (Lepidoptera. Saturniidae): A study of cryofixed material. Cell Tissue Res 266 : $427-440$. 